\title{
MEANING AND CREDIBILITY OF FORWARD-LOOKING DISCLOSURES: EVIDENCE FROM AN ENTRY GAME* $^{*}$
}

\author{
DOI: 10.17261/Pressacademia.2020.1328 \\ JEFA- V.7-ISS.4-2020(7)-p.362-373
}

\section{Hakan Karabacak}

Social Sciences University of Ankara, Audit and Risk Management Department, Ulus, Ankara, Turkey. hakan.karabacak@asbu.edu.tr, ORCID: 0000-0001-6321-088X

Date Received: November 5, $2020 \quad$ Date Accepted: December 22, 2020

To cite this document

Karabacak,H. (2020). Meaning and credibility of forward-looking disclosures: evidence from an entry game. Journal of Economics, Finance and Accounting (JEFA), V.7(4), p.363-373.

Permanent link to this document: http://doi.org/10.17261/Pressacademia.2020.1328

Copyright: Published by PressAcademia and limited licensed re-use rights only.

\begin{abstract}
Purpose- The study aims to find and analyze the equilibria for the forward-looking disclosures using game theory and to investigate the information signaling mechanism of such disclosures focusing on the credibility and meaning of them.

Methodology- The study uses a cheap-talk game setting as a special form of signaling game in which forward-looking information are examined as costless, nonbinding and non-verifiable claims sent to a potential Entrant by the Incumbent firm.

Findings- Equilibria are derived and neologism-proofness refinement is applied to rule out the implausible equilibria. Informative equilibrium exists only if the players' preferences are more closely aligned. Entrant's strategy is critical to determine which equilibrium is plausible. Under entry strategy, informative equilibrium is plausible and rules out the uncommunicative equilibria. However, under non-entry strategy, informative equilibrium fails to be plausible.

Conclusion- Only under the entry strategy, the Incumbent should disclose its private information, whereas, under non-entry strategy, the Incumbent should not reveal its private information. Furthermore, the uncommunicative equilibria indicate that despite the Entrant's pessimism about future, the Entrant prefers to choose entry strategy when the entry cost is sufficiently low. Contrarily, despite the Entrant's optimism, non-entry becomes optimal when the entry cost is relatively high.
\end{abstract}

Keywords: Forward-looking information, disclosure, cheap-talk, neologism-proofness

JEL Codes: C72, D82, M41

\section{INTRODUCTION}

Traditional annual reports are generally retrospective and include past operating and financial data. However, users of business reporting need also forward-looking perspective to properly evaluate the opportunities and risks and to make more informed decisions. Moving beyond the scope of already existing financial reporting system, voluntary disclosure of forwardlooking information (FLI) enhances the relevance and usefulness of business reporting.

Forward-looking disclosures goes back to early 1970's, Securities and Exchange Commission (SEC) in US adopted policies encouraging issuers to disclose voluntarily forward looking information both in their public filings and in public statements generally. In 1994, American Institute of Certified Public Accountants (AICPA) Special Committee on Financial Reporting (the Jenkins Committee) drew attention to the forward-looking information in its report entitled "Improving Business Reporting A Customer Focus". In this report, forward-looking information was categorized as a type of company-specific information that users need and also, a major component of the suggested Model of Business Reporting.

FLI is defined as any prediction or information that aids prediction. It includes management's plans, assessments of opportunities and risks, and forecasted data (AICPA, 1994). AICPA (1994) notes that FLI comprises both of financial and non-

\footnotetext{
* This study was derived from the Ph.D. thesis titled "Game Theory and an Equilibrium Model in Public Disclosure" which was completed by the author in 2008 under the consultancy of Prof. Dr. Orhan ÇELiK in the Institute of Social Sciences of Ankara University and presented in the IV. International Conference on Applied Economics and Finance held in 28-30 November 2018 in Aydın.
} 
financial items and includes (1) opportunities and risks, including those resulting from key trends, (2) management's plans including critical success factors and (3) comparison of actual business performance to previously disclosed opportunities, risks, and management's plans.

The qualitative part of forward-looking disclosure is neither mandatory nor specifically regulated. In fact, this part has subjective and non-accounting content. It entails narrative and descriptive information. Especially the subjective and nonaccounting parts of forward-looking disclosures lay ground the use of cheap-talk models since the firms might announce any messages regardless of their private information. Cheap-talk models is characterized by costless, non-binding and nonverifiable signals that simply qualified as claims. The sender's messages are just talk, which not necessarily linked to senders' private information. Standard model of cheap-talk game was formally introduced by Crawford and Sobel (1982) in which the informed sender sends a message to uninformed receiver and then, by responding the messages, the receiver chooses the payoff-relevant actions to both players.

The study aims to find and analyze the equilibria for the forward-looking disclosures in a hypothetical entry game played by an Incumbent and a potential Entrant and also to investigate the information signaling mechanism of such disclosures focusing on the credibility and meaning of them. The game builds on the model and concepts of Crawford and Sobel (1982) to check the necessary conditions for FLI to be informative. Also the reliability and robustness of equilibrium outcomes are tested by neologism-proofness criteria as specified in Farrell (1993). In fact, the meaning and credibility dimensions of the messages in cheap-talk games underpin neologism-proofness criteria. In Turkey, there is not any previous study analyzing the $\mathrm{FLI}$ as cheap-talk in an entry game setting. In this scope, this study makes a theoretical contribution both examining the forward-looking disclosures as part of the strategic analysis and also investigating the information signaling mechanism of such disclosures. This study is the first to find and analyze equilibria for the FLI and to analyze the meaning and credibility of such information in a hypothetical entry game.

The rest of paper is organized as follows. The next section surveys the literature. Section 3 describes the entry game and sets forth the equilibria. Section 4 discusses the equilibrium results and refines them based on the neologism-proofness criteria. The last section closes with concluding remarks.

\section{LITERATURE REVIEW}

Disclosing favorable information possibly encourages new competitors to enter and can damage the competitive position of the firm in product markets. The loss in profits due to the increased competition is qualified as proprietary cost (Verrecchia, 1983). Researchers indicate that disclosure decision of the firms is influenced by the proprietary cost concerns (among others, Wagenhofer, 1990; Darrough and Stoughton, 1990; Feltham and Xie, 1992; Darrough, 1993; Newman and Sansing, 1993; Gigler, 1994). Darrough and Stoughton (1990) firstly focused on a stylized model of static entry game, where the cost of disclosing proprietary information takes the form of an increased probability of entry.

When disclosure is in the form of FLI, the credibility issue gain importance for the end users of such information due to its information content. Though a substantial part of scientific research conceptualized FLI in the form of earnings forecasts (e.g. Lev and Penman, 1990; Frankel et al., 1995; Clarkson et al., 1999; Baginski, et al. 2004; Kim and Shi, 2011), as indicated in Beattie et al., 2004; O'Sullivan et al., 2008; Kent and Ung, 2003), forward-looking disclosures are mostly qualitative or nonfinancial character in nature. AICPA (1994) notes that users of the business reporting find useful management's perspective on two types of FLI: (1) opportunities and risks, and (2) management's plans for the future. Although users are interested in forecasted financial and operating data, they generally believe that management should not include those forecasts in business reporting.

Forward-looking disclosure enhances the investor's understanding about the business context and its future, and helps them for their capital allocation decisions. However, non-accounting and/or qualitative parts of forward-looking disclosures complicates the monitoring of the accuracy of the disclosed information for stakeholders and adds to FLI a non-verifiable character. Non-accounting and/or qualitative disclosures (or corporate narratives) can be easily discharged as cheap-talk by end users of such disclosures since it is costless to convey and relatively difficult to verify (Baginski et al., 2016). Clatworthy and Jones (2006) notes that the chairman's letter giving a summary of the firm's performance and activities is one of the parts in which non-verifiable forward-looking information is mostly located. Such FLI bears the characteristics of cheap-talk since they include not binding commitments and do not directly affect payoffs. As argued in Stocken (2000), in the lack of a mechanism to test voluntary disclosure, it would be considered as non-credible. The end-users do not trust and ignore it. Stocken (2000) analyzes the credibility of a manager's disclosure of privately observed non-verifiable information in a repeated cheap-talk game setting and indicates that managers do not make any informative disclosures (or, communication 
does not occur) in the single-period game, whereas in the repeated game, the manager almost always truthfully reveals his private information. The empirical evidence by Li et al. (2020) supports the arguments of Stocken (2000) that voluntary disclosures have higher credibility in the repeated game than in the one-stage game. From another perspective, D'Augusta and DeAngelis (2017) notes that accounting information is able to prevent "cheap talk" in qualitative disclosure by providing a benchmark to evaluate the truthfulness of managers' statements. This result also implies the non-verifiable and non-binding character of the FLI's non-accounting parts.

A relatively small branch of literature (Farrell, 1987; Park, 2002) analyze cheap-talk in the context of an entry game and in this scope, focus on the pre-play communication among players to achieve coordination in the underlying game. These studies indicate that preannouncement of entry achieves some degree of coordination among potential Entrants into a naturalmonopoly industry in the game of complete information (i.e. Farrell, 1987) or in the game, where the potential Entrants have their privately known characteristics, or types (i.e. Park, 2002). Furthermore, informational signaling mechanism of cheaptalk have been investigated by numerous studies (among others, Farrell and Gibbons (1989), Rabin (1990), Matthews et al., (1991), Farrell (1993), Rabin and Sobel (1996), Chen et al. (2008), de Groot Ruiz et al. (2015) to determine how the coordination and competition dynamics among the players affect the payoffs and which equilibria describes how the game will be played.

This study analyzes FLI as cheap-talk in the one-stage entry game setting due to its non-verifiable and nonbinding character and investigates the informational signaling mechanism of such disclosures focusing on the credibility and meaning of them.

\section{METHODOLOGY}

The study uses cheap-talk game setting as a special form of signaling game in which forward-looking information are examined as costless, nonbinding and non-verifiable claims. The following sub-sections describes the entry game played by an Incumbent and a potential Entrant and sets forth the equilibria.

\subsection{Description of the Game}

The cheap-talk game involves two players: Incumbent firm (I) and potential Entrant (E) are included in the model as sender and receiver, respectively. Based on in-company analysis, the Incumbent firm is endowed with private information of forwardlooking character such as the Incumbent's forecasts about the sector profitability or in general terms, predicted any information favorable or unfavorable, financial or non-financial in nature about future conditions. This paper assumes that the private information parameters take two possible values, $t_{H}$ (high type) or $t_{L}$ (low type) for its favorable or unfavorable content, respectively. For the potential Entrant, the market entry yields profit under $t_{H}$, but causes loss under $t_{L}$. The classification of the Incumbent's private information as favorable or unfavorable from the viewpoint of the Entrant is originated from Darrough and Stoughton (1990). However, unlike the assumption of Darrough and Stoughton (1990), in this study, the Incumbent's private information is assumed to be of forward-looking character to allow the analysis within the scope of a cheap-talk entry game.

The Incumbent's private information, which creates an information asymmetry between the players, is modeled by "types", as described by Harsanyi $(1967,1968)$. Nature draws a type for the Incumbent from a set of feasible types, $T=\left\{t_{H}, t_{L}\right\}$ according to a probability distribution. Prior beliefs: $p\left(t_{H}\right)>0$ and $p\left(t_{L}\right)>0$ and $p\left(t_{H}\right)+P\left(t_{L}\right)=1$.

The messages, $\mathrm{FLI}_{1}$ or $\mathrm{FLI}_{2}$ are signaled from the Incumbent to potential Entrant. Message is assumed to be rich enough to announce what needs to be announced, which means $M=T$. Following the random draw by the nature, the Incumbent chooses a message from a set of feasible messages, $M=\left\{\mathrm{FLI}_{1}, \mathrm{FLI}_{2}\right\}$. In the model, the actions of Entrant, "enter" and "not enter", are denoted by $A_{1}$ and $A_{0}$, respectively. The Entrant observes the messages and then, chooses an action from a set of feasible actions, $A=\left\{a_{1}, a_{0}\right\}$

In cheap-talk games, payoffs are given by $U_{1}(T, A)$ and $U_{E}(T, A)$. This paper draws guidance from the notation of Darrough and Stoughton (1990)'s entry game, the following notation is used to determine the payoff levels of the firms:

The payoff of Incumbent (I), Entrant (E) and the monopolist (M) under duopoly in $t_{H}$ :

$\theta^{i}, \quad i=I, E, M$

The payoff of Incumbent (I), Entrant $(E)$ and the monopolist $(M)$ under duopoly in $t_{L}$ :

$\theta_{i}, \quad i=I, E, M$ 
These definitions imply that $\theta^{i}>\theta_{i} \quad i=I, E, M$

This condition for each payoff can be concisely described as follows:

$\theta^{\prime}>\theta^{\prime}$

$\Theta^{\mathrm{E}}>\theta_{\mathrm{E}}$

$\theta^{M}>\theta_{M}$

Farrell (1987) considers that the sunk cost of entry as a significant determinant of deciding on entry (or not) in some markets such as computer software, telephone switching equipment or nationwide fiberoptic telephone networks. It is assumed that entry incurs a cost of $\mathrm{K}_{\mathrm{E}}$. This assumption is originated from Darrough and Stoughton (1990) which establishes a dynamic game of incomplete information. Due to the fact that the cheap-talk games fall within the branch of dynamic games of incomplete information, the theoretical interaction of the entry cost with the other variables, $\Theta^{\mathrm{E}}$ and $\Theta_{\mathrm{E}}$, does not differ in the context of a market entry game.

$\theta^{E}>K_{E}>\theta_{E}>0$

This assumption guarantees that the potential Entrant will stay out following the forward-looking disclosure in $t_{L}$ but will surely enter the market following the forward-looking disclosure in $t_{H}$. Two possibilities exist concerning the relative amounts of $\Theta_{M}$ ile $\Theta^{\prime}$ in tandem with the condition (1),

$\theta_{M} \geq \theta^{I} \rightarrow \theta^{M}>\theta_{M} \geq \theta^{1}>\theta_{1}$

$\theta_{M}<\theta^{\prime} \rightarrow \theta^{M}>\theta^{I}>\theta_{M}>\theta_{1}$

The corollary of both the conditions (3) and (4) reveals that $\theta^{\mathrm{M}}>\theta^{\mathrm{I}}$ and $\theta_{\mathrm{M}}>\theta_{1}$. To be a clearer indication, this paper uses a signaling game model taken from Cho and Kreps (1987) represented as extensive form in Figure 1.

\section{Figure 1: Cheap-Talk Entry Game}

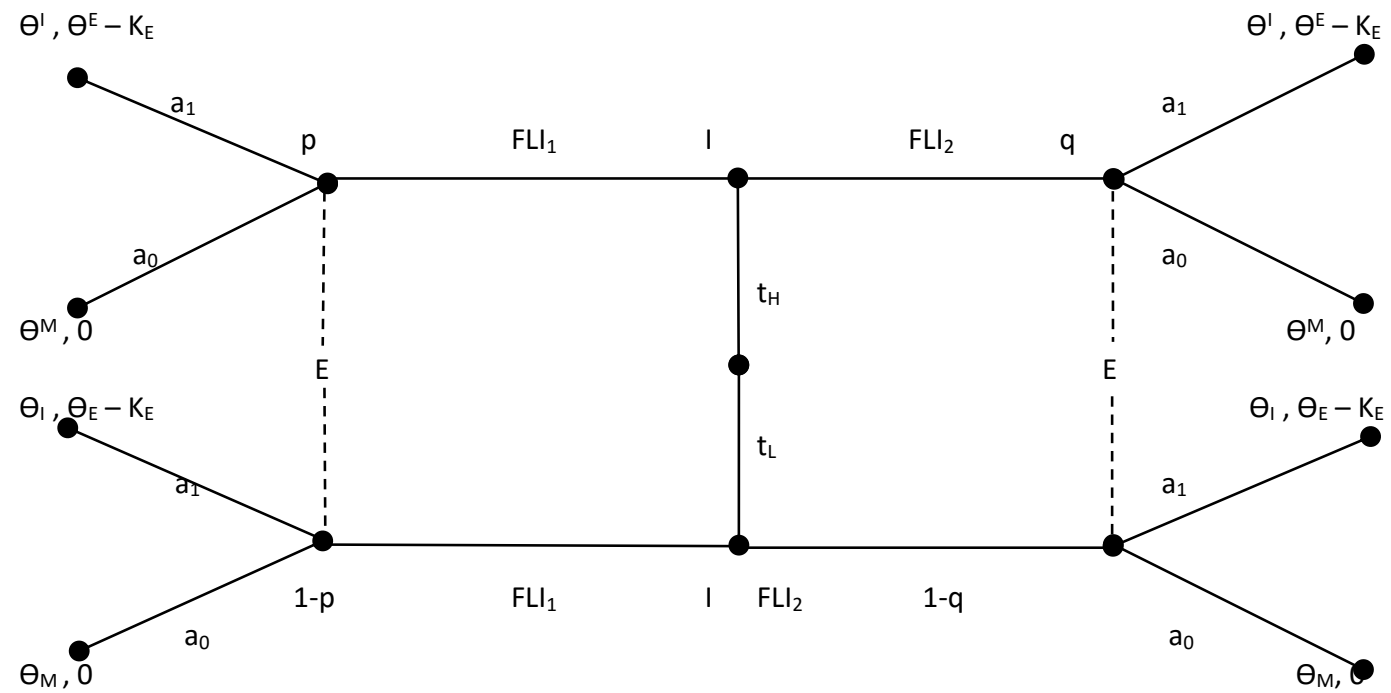

The play of the game flows from an initial move at the middle node to end nodes at the left and right edges. The nature moves first and draws a type for the Incumbent. The Incumbent moves second and sends the messages. After observing the messages, the Entrant chooses the actions. The Incumbent's payoff is listed before the Entrant's payoff in the end nodes of the Figure 1.

This study extent the main theme of Darrough and Stoughton (1990) to forward-looking disclosures establishing a cheap-talk setting in the context of an entry game. Darrough and Stoughton (1990) establishes a dynamic game of incomplete information between the Incumbent monopolist and the potential Entrant. In fact, the cheap-talk games (in general, signaling 
games) are one of the branch of dynamic games of incomplete information involving two players, in which sender as an informed player sends observable messages and receiver as an uninformed player takes strategic actions. Hence, as in Darrough and Stoughton (1990), this study uses the common algorithm to identify the perfect Bayesian equilibriums in a dynamic game of incomplete information and to explain the strategic interactions between the Incumbent and potential Entrant. However, unlike the model of Darrough and Stoughton (1990), this study analyzes FLI as costless, nonbinding and non-verifiable claims sent to a potential Entrant by the Incumbent firm and establishes a cheap-talk model as a special form of signaling games.

\subsection{The Equilibrium Analysis}

The paper employs the perfect Bayesian (Nash) equilibrium, and its solution technique and concepts can be found, for the most part, in Gibbons (1992). The perfect Bayesian equilibrium, which includes the set of mutually optimal strategies and beliefs, is indicated as:

$$
\left[\left(\mathrm{FLI}_{1,2}\right)^{*},\left(\mathrm{FLI}_{1,2}\right)^{* *} ;\left(\mathrm{a}_{1,0}\right)^{*},\left(\mathrm{a}_{1,0}\right)^{* *} ; \mathrm{p}, \mathrm{q}\right]
$$

This indication is explained as follows: $\left(\mathrm{FLI}_{1,2}\right)^{*}$ - action of I in $\mathrm{t}_{\mathrm{H}} ;\left(\mathrm{FLI}_{1,2}\right)^{* *}$ - action of I in $\mathrm{t}_{\mathrm{L}} ;\left(\mathrm{a}_{1,0}\right)^{*}$ - action of $\mathrm{E}$ following $\mathrm{FLI}_{1}$, and $\left(a_{1,0}\right)^{* *}$ - action of $E$ following $\mathrm{FLI}_{2}$. In the last place, posterior beliefs $(\mu), p$ and $q$, are included. The beliefs describe Entrant's uncertainty about the Incumbent's types. Due to Bayes rule, the prior beliefs are replaced by the posterior beliefs $(\mu)$, denoted by

$$
\mathrm{p}=\mathrm{P}\left(\mathrm{t}_{\mathrm{H}} \mid F \mathrm{FI}_{1}\right), 1-\mathrm{p}=\mathrm{P}\left(\mathrm{t}_{\mathrm{L}} \mid F \mathrm{I}_{1}\right), \mathrm{q}=\mathrm{P}\left(\mathrm{t}_{\mathrm{H}} \mid F \mathrm{IL}_{2}\right), 1-\mathrm{q}=\mathrm{P}\left(\mathrm{t}_{\mathrm{L}} \mid F \mathrm{FI}_{2}\right)
$$

The equilibria are analyzed under two scenarios. In the scenario 1 , the above-mentioned conditions, from 1 to 4 , apply and the players' preferences over the actions diverge and only the pooling equilibrium exists. In the scenario 2 , the players' preferences are sufficiently aligned and hence, the separating equilibrium exists if and only if $\Theta^{\mathrm{M}} \geq \theta^{\mathrm{I}}$.

\section{Scenario 1: $\theta^{\mathrm{M}}>\theta^{\mathrm{I}}$}

The prior beliefs, $P\left(t_{H}\right)$ and $P\left(t_{L}\right)$, fall into to three broad categories: high $(0.5<P(T)<1)$, low $(0<P(T)<0.5)$ and equal to each other $(P(T)=0.5)$. In pooling equilibrium, the Entrant maintains the prior beliefs for these intervals after all messages (on and off the equilibrium path).

Unlike signaling games, in cheap-talk games, pooling equilibrium always exists. In the entry game in which FLI is announced as signal, it is a pooling equilibrium for the Incumbent to play any pooling strategy (pooling on $\mathrm{FLI}_{1}$ or $\mathrm{FLI}_{2}$ ), for the Entrant to maintain the prior belief $\left(p\left(t_{H}\right)>0\right.$ and $\left.p\left(t_{L}\right)>0\right)$ after all messages (on and off the equilibrium path), and for the Entrant to take the action from a set of feasible actions, $a=\left\{a_{1}, a_{0}\right\}$ after all messages. Thus, the pooling equilibria can be formally defined as:

Pooling equilibrium 1: There exists a perfect Bayesian equilibrium in which both types choose to send $\mathrm{FLI}_{1}$, and the entry occurs for any $p>K_{E}-\theta_{E} / \theta^{E}-\theta_{E}$ and $q>K_{E}-\theta_{E} / \theta^{E}-\theta_{E}$. Symbolically,

$$
\left[\left(F L I_{1}, F L I_{1}\right),\left(a_{1}, a_{1}\right), p>K_{E}-\theta_{E} / \theta^{E}-\theta_{E}, q>K_{E}-\theta_{E} / \theta^{E}-\theta_{E}\right]
$$

Pooling equilibrium 2: There exists a perfect Bayesian equilibrium in which both types choose to send $\mathrm{FLI}_{2}$, and the entry occurs for any $q>K_{E}-\theta_{E} / \Theta^{E}-\theta_{E}$ and $p>K_{E}-\theta_{E} / \Theta^{E}-\theta_{E}$. Symbolically,

$$
\left[\left(F L I_{2}, F L I_{2}\right),\left(a_{1}, a_{1}\right), q>K_{E}-\theta_{E} / \theta^{E}-\theta_{E}, p>K_{E}-\theta_{E} / \theta^{E}-\theta_{E}\right]
$$

Proof: The proof the pooling equilibrium 1 would only be sufficient since the same common algorithm is used to identify the perfect Bayesian equilibria, which are based on a set of conditions as defined broadly in Fudenberg and Tirole (1991). The potential Entrant prefers the action of "enter" if the expected payoff from entering the market is higher than that under a "not enter" in the pooling strategy on $\mathrm{M}_{\mathrm{p}}$. Thus, the following condition has to be satisfied:

p. $\left(\theta^{\mathrm{E}}-\mathrm{K}_{\mathrm{E}}\right)+(1-p) \cdot\left(\Theta_{\mathrm{E}}-\mathrm{K}_{\mathrm{E}}\right)>0$

The left-hand side of condition (3) represents the expected payoff of "enter", whereas the right-hand side represents the expected payoff of "not enter". This can be rearranged to give the equivalent condition,

$p>K_{E}-\theta_{E} / \theta^{E}-\theta_{E}$ 
Rewriting the inequality (6), it is obtained condition (7),

$K_{E}<p\left(\theta^{E}-\theta_{E}\right)+\theta_{E}$

The Entrant's optimal strategies in terms of the posterior belief, $\mathrm{p}$, following $\mathrm{FLI}_{1}$ are:

$$
a *(p) \quad \begin{cases}a_{1} & \text { if } p>K_{E}-\Theta_{E} / \Theta^{E}-\theta_{E} \\ a_{0} & \text { if } p<K_{E}-\Theta_{E} / \Theta^{E}-\theta_{E} \\ a_{0}, a_{1} & \text { if } p=K_{E}-\Theta_{E} / \Theta^{E}-\theta_{E}\end{cases}
$$

The Entrant's information set corresponding to $\mathrm{FLI}_{1}$ is on the equilibrium path, so the Entrant's belief $(p, 1-p)$ at this information set should be determined by Bayes' rule and the Incumbent's strategy. Given this belief, the Entrant's best response following $F L_{1}$ is to play $a_{1}$ for $p>K_{E}-\theta_{E} / \theta^{E}-\theta_{E}$, so the Incumbent in types $t_{H}$ and $t_{L}$ earn $\Theta^{\prime}$ and $\theta_{1}$, respectively. To determine whether both of the Incumbent types are willing to choose $\mathrm{FLI}_{1}$, it is required to specify how the Entrant would react to $\mathrm{FLI}_{2}$, so it remains to consider the Entrant's belief at the information set corresponding to $\mathrm{FLI}_{2}$, and the optimality of choosing entry strategy given this belief. Following $\mathrm{FLI}_{2}$, the optimal strategies of the Incumbent depending on the payoff levels and entry cost are the same with the intervals of $p$. However, the corresponding information set following $\mathrm{FLI}_{2}$ is off the equilibrium path. The Incumbent cannot earn more by choosing $\mathrm{FLI}_{2}$ in each type, since the signal has no direct payoff implications in cheap-talk games. Thus, the Incumbent has no incentive to deviate from playing $\mathrm{FLI}_{2}$ in $\mathrm{t}_{\mathrm{H}}$ and $\mathrm{t}_{\mathrm{L}}$.

Scenario 2: $\theta^{\mathrm{M}} \geq \boldsymbol{\theta}^{\mathrm{I}}$

The interesting question in a cheap-talk game is whether non-pooling equilibria exist (Gibbons, 1992). In 2-types, 2-messages, 2 -actions entry game, non-pooling equilibria corresponds to the separating equilibria which is informative since each message reveals its type by sending different messages. In cheap-talk games, the message has no direct effect on the players' payoffs and only the informative messages can indirectly affect both player's payoffs by changing the receiver's belief about the types, hence resulting a change in receiver's action.

Crawford and Sobel (1982) indicates three necessary conditions for cheap-talk to be informative. The first necessary condition is about the sender's preferences about the actions. Hereunder, the different sender-types must have different preferences over the receiver's actions for the cheap-talk to be informative. The second necessary condition is about the receiver's preferences. The receiver must prefer different actions depending on the sender's type. If the preferences of receiver are independent of the types, then there is no reason to send any signal. The last necessary condition is that receiver's preferences over actions must not be completely opposed to sender's. The opposition between the players' preferences makes impossible the informative communication since the sender would like to mislead the receiver. To illustrate whether the separating equilibria exist, the existence of these conditions should be analyzed in the entry game.

To illustrate the first necessary condition, in the entry game, the Incumbent types, $t_{H}$ and $t_{L}$, have the same preferences over the actions. Since $\theta^{M}>\theta^{\prime}$ and $\theta_{M}>\theta_{1}$, both Incumbent types prefer $a_{1}$ to $a_{0}$. So, the first condition for cheap-talk to be informative is not satisfied. However, the second necessary condition is satisfied: The Entrant prefers the different actions depending on the Incumbent's type, so that the Entrant prefers $a_{1}$ in $t_{H}$, and $a_{0}$ in $t_{L}$. The third necessary condition is also satisfied, since the Entrant's preferences over actions are not be completely opposed to Incumbent's.

Crawford and Sobel (1982) underlines that more communication can be possible through cheap-talk in case the preferences of players are more closely aligned, but perfect communication cannot occur unless the players' preferences are perfectly aligned. As noted in Gibbons (1992), the interests of the players are perfectly aligned, in the sense that given the sender's type, the players agree on which action should be taken. In fact, in the 2-types, 2-messages, 2-actions entry game, separating equilibrium corresponds the alignment of the players' preferences, which requires that all necessary conditions of Crawford and Sobel (1982) are satisfied. However, in the entry game, the players' interests are not aligned. In $t_{H}$, the Entrant's preference $\left(a_{1}\right)$ is opposed to the Incumbent's $\left(a_{0}\right)$, while in $t_{L}$, both player prefers the same action $\left(a_{0}\right)$. Both types would like the Entrant to believe that its type is always in $t_{L}\left(T=t_{L}\right)$, but the Entrant cannot believe such a claim.

In fact, in cheap-talk games, completely opposite and aligned preferences of the players represent two extreme cases. In the cases of pure conflict, a message loses its informativeness and thus ignored by the receiver when the player's preferences are perfectly opposed. As also indicated in Farrell (1987), an existence of even a small amount of conflict limits the perfect coordination and the degree of compliance of the preferences determines the effectiveness of communication. On the other hand, in the cases of pure coordination, a message can convey useful information and cheap-talk can be very credible. As noted in Crawford (1998), "the message is cheap-talk in that players care only about its information content, not about the 
message per se". The players are likely to believe informational claims by the other when the players agree on the optimal actions contingent on any information (Rabin, 1990). However, in most strategic situations, there is neither pure conflict nor pure coordination. Likewise, in the entry game, the players' preferences are neither diametrically opposed nor fully aligned. Thus, the payoffs of the Incumbent in $t_{H}$ should fulfill the condition, $\theta^{\mathrm{M}} \geq \theta^{\mathrm{I}}$ to sufficiently ensure the alignment of the preferences for separating equilibrium to emerge. This new condition adds informativeness to the communication by bringing the players' preferences closer.

Scenario 2 transforms the alternative conditions (3) and (4) to $\theta^{M} \geq \theta_{M} \geq \theta^{I}>\theta_{1}$ and $\theta^{M} \geq \theta^{I}>\theta_{M}>\theta_{1}$ respectively, also the condition 1(c) to $\Theta^{\mathrm{M}} \geq \Theta_{\mathrm{M}}$ to ensure the condition (3) Thus, both first and third necessary conditions of the Crawford and Sobel (1982) are satisfied and separating equilibrium exists if and only if $\Theta^{\mathrm{M}} \geq \theta^{\prime}$ since the player's interest sufficiently coincide. Formally, in the separating equilibrium, the Incumbent's strategy is $\left(m\left(t_{H}\right)=F L I_{1,2}, m\left(t_{L}\right)=F L I_{2,1}\right)$, the Entrant's beliefs are $\mu\left(t_{L, H} \mid t_{L, H}\right)=1$ and $\mu\left(t_{L, H} \mid t_{H, L}\right)=0$, and the Entrant's strategy is $\left.\left[a\left(t_{H}\right)=a_{1}, a\left(t_{L}\right)=a_{0}\right)\right]$. The separating equilibria can separately be defined as:

Separating Equilibrium 1 (Separating $t_{H}$ with playing $\mathrm{FLI}_{1}$ ): There exists a perfect Bayesian equilibrium in which $\mathrm{t}_{\mathrm{H}}$ chooses to send $\mathrm{FLI}_{1}$ and $\mathrm{t}_{\mathrm{L}}$ to send $\mathrm{FLI}_{2}$, and the Entrant chooses $\mathrm{a}_{1}$ following $\mathrm{FLI}_{1}$ and $\mathrm{a}_{0}$ following $F L_{2}$, if and only if $\Theta^{\mathrm{M}} \geq \Theta^{\prime}$. Symbolically,

$$
\left[\left(F L I_{1}, F L I_{2}\right),\left(a_{1}, a_{0}\right), p=1, q=0\right]
$$

Separating Equilibrium 2 (Separating $t_{L}$ with playing $F L_{1}$ ): There exists a perfect Bayesian equilibrium in which $t_{L}$ chooses to send $\mathrm{FLI}_{1}$ and $\mathrm{t}_{\mathrm{H}}$ to send $\mathrm{FLI}_{2}$, and the Entrant chooses $\mathrm{a}_{0}$ following $\mathrm{FLI}_{1}$ and $\mathrm{a}_{1}$ following $\mathrm{FLI}_{2}$, if and only if $\Theta^{\mathrm{M}} \geq \Theta^{\prime}$. Symbolically,

$$
\left[\left(F L I_{2}, F L I_{1}\right),\left(a_{0}, a_{1}\right), p=0, q=1\right]
$$

In the market entry game, for these strategies and beliefs to the equilibria, each type of Incumbent must prefer to say the truth, thereby inducing the action $\mathrm{a}_{0}$ rather than to lie and the Entrant must believe the revealed information.

Proof: If the Incumbent plays the separating strategy $\left(\mathrm{FLI}_{1}, \mathrm{FLI}_{2}\right)$, then the posterior beliefs are $\mathrm{p}=1$ and $\mathrm{q}=0$. The Entrant's best responses to these beliefs are $a_{1}$ and $a_{0}$, so $t_{H}$ and $t_{L}$ earns payoffs $\theta^{\prime}$ and $\theta_{M}$, respectively. Since the condition $\theta^{M} \geq \theta^{\prime}$ holds, type $t_{H}\left(t_{L}\right)$ does not has an incentive to deviate by playing $\mathrm{FLI}_{2}\left(\mathrm{FLI}_{1}\right)$ and has willing to choose $\mathrm{FLI}_{1}\left(\mathrm{FLI}_{2}\right)$. Likewise, if the Incumbent plays the separating strategy $\left(\mathrm{FLI}_{2}, \mathrm{FLI}_{1}\right)$, then the posterior beliefs are $\mathrm{p}=0$ and $\mathrm{q}=1$. Since the condition $\Theta^{\mathrm{M}}$ $\geq \Theta^{\prime}$ holds, type $t_{H}\left(t_{L}\right)$ do not has an incentive to deviate by playing $F L_{1}\left(F_{L} I_{2}\right)$ and choosing $F I_{2}\left(F L I_{1}\right)$ is optimal.

\section{FINDINGS AND DISCUSSION OF THE EQUILIBRIUM RESULTS}

The condition (6) implies that entry cost, $\mathrm{K}_{\mathrm{E}}$, should be small enough to validate the condition and to encourage the Entrant to choose $a_{1}$. Only if the amount of $K_{E}$ sufficiently decreases, the value of the right-hand side of (6) converges to zero, given the constant values of $\Theta^{\mathrm{E}}$ and $\Theta_{\mathrm{E}}$. Hence, as the entry cost decreases, $\mathrm{a}_{1}$ becomes optimal for a wider interval of $p$, where $0<$ $p<1$. This implies that the Entrant prefers to choose entry in case the entry cost is sufficiently low, even if the Entrant believes that unfavorable future conditions most probably will exist (for the interval of $p$, where $0<p<0.5$ ). In fact, sufficiently low amounts of entry cost overcome the Entrant's pessimism about future.

Contrarily, as the entry cost increases, then the choose of entry becomes optimal only for relatively high values of $p$ to validate the condition (6). This means that the Entrant would restrain to enter the market even in high ratios of $p$ if the entry cost is relatively high. Thus, this brief analysis supports the intuitive inference that relatively high amounts of the entry cost are deterrent for the Entrant to choose the entry even if Entrant believes that favorable future conditions will likely exist (for the interval of $p$, where $0.5<p<1$ ). Relatively high amounts of entry cost overshadow the Entrant's optimism. The condition (6) also implies that if the entry cost is relatively high, entry can become not preferable even for high values $\Theta^{\mathrm{E}}$. However, given the constant values of $\mathrm{K}_{\mathrm{E}}$ and $\Theta_{\mathrm{E}}$, as the amount of $\Theta^{\mathrm{E}}$ increases, right-hand side of the condition (6) also decreases and the Entrant becomes more biased to choose entry as part of the optimal strategy even in low ratios of $p$, where $0<p<0.5$. Conversely, as the numerator of right hand side of condition (6) increases (increase in $\mathrm{K}_{\mathrm{E}}$ ), non-entry becomes preferable even in the high ratios $p$, where $0.5<p<1$ and hence, the Entrant's tendency to stay out of the market increases.

The corollary of the condition (7) is that the high values of posterior belief, $p$ or/and Entrant's payoff, $\Theta^{\mathrm{E}}$, overcome the relatively high values of entry cost encouraging the potential Entrant to choose the entry. In fact, given the pessimistic predictions about future (for the interval of $p$, where $0<p<0.5$ ), the payoff should be at a level to cover the entry cost. As the $\Theta^{\mathrm{E}}$ increases, the entry tendency also increases and entry becomes optimal even for high values of entry cost, given a constant value of $p$. Contrarily, as the $\Theta^{E}$ relatively decreases, the entry can become not preferable even in the optimistic predictions about future conditions (for the interval of $p$, where $0.5<p<1$ ), given a constant value of $K_{E}$. In sum, this analysis 
gives evidence that the Entrant's payoffs and entry cost along with the predictions expressed in posterior beliefs, are critical to decide whether to enter or not enter. The payoff resulted from entry in $t_{H}$, (i.e., $\Theta^{\mathrm{E}}$ ), has clearly an encouraging effect, while $K_{E}$ has a discouraging effect on the choose of entry.

In cheap-talk, the credibility problem is associated with the informativeness of the messages. In case the availability of incentives to lie, the credibility of the messages and informativeness of the equilibrium are eroded. Crawford and Sobel (1982) examines the credibility and informativeness concepts considering the degree of conflict and common interest between the players. As the interests of the players are more closely aligned, the messages can be more credible and the game can be more informative through increased communication.

However, cheap-talk games are characterized by multiplicity of the perfect Bayesian equilibria. As noted in Farrell (1993), there always exist a "babbling equilibrium" in cheap-talk in which all messages are interpreted as meaningless. In "babbling" equilibrium outcome, the receiver's response is equal to her ex-ante optimal choice (Chen et al., 2008). Furthermore, Farrell (1993) highlights a second, more fundamental problem in cheap-talk to be informative. Even absent credibility problems, any permutation of messages across meanings gives another equilibrium and this problem creates another kind of multiplicity of equilibrium in cheap-talk. The standard refinement criteria for signaling games such as Intuitive Criteria of Cho and Kreps (1987) and Universal Divinity of Banks and Sobel (1987), which can rule out the implausible equilibria by restricting the interpretations of messages not used in equilibrium (unused, out-of-equilibrium messages) are ineffective to eliminate the implausible equilibria in cheap-talk. In the seminal works, Farrell $(1985,1993)$ introduced the neologism-proofness criteria to refine perfect Bayesian equilibria for cheap-talk games.

Neologism-proofness criteria assigns an important role to language to coordinate the actions and focuses on the literal meaning of the messages in quest for meaningful neologisms. If the credible neologisms are believed, then it imposes a condition on equilibrium that no such credible neologism is available and attractive relative to the equilibrium. On this equilibrium condition called neologism-proofness, no player should have an incentive to introduce a credible neologism. If there is any credible neologism, then the putative equilibrium does not describe how the game will be played (Farrell, 1993). As noted in Matthews et al. (1991), this contribution was fundamental, introducing the concept of a rich language with literal meanings through which the sender breaks the putative equilibrium. In the entry game, the neologism-proofness criteria will be examined in the scope of above-mentioned scenarios.

\section{Scenario 1: $\theta^{\mathrm{M}}>\theta^{\mathrm{I}}$}

In tandem with the condition (1), the alternative conditions (3), $\theta^{M}>\theta_{M} \geq \theta^{\prime}>\theta_{1}$ and (4), $\theta^{M}>\theta^{\prime}>\theta_{M}>\theta_{1}$, apply respectively. The corollary of both conditions indicates that the monopoly payoff is higher than the Incumbent's, $\theta^{M}>\theta^{\prime}$ and $\theta_{M}>\theta_{1}$. In this scenario, the pooling equilibrium is the unique perfect Bayesian equilibrium. According to the results of Farrell (1993), if the sender's preferences over receiver's beliefs are independent of the types, then the uncommunicative perfect Bayesian equilibrium is neologism-proof. In the entry game, $t_{H}$ and $t_{L}$ strictly prefer $a_{0}$ to $a_{1}$. Hence, the unique perfect Bayesian equilibrium is uncommunicative and is also neologism-proof in the entry game.

\section{Scenario 2: $\theta^{\mathrm{M}} \geq \theta^{\mathrm{I}}$}

In this scenario, the updated conditions (3), $\theta^{M} \geq \theta_{M} \geq \theta^{I}>\theta_{1}$, and (4), $\theta^{M} \geq \theta^{I}>\theta_{M}>\theta_{1}$, apply respectively. Farrell (1993) notes that if sender and receiver have identical interests (the case of pure communication), then full communication is a neologism-proof equilibrium. To make an evaluation on the existence of neologism-proof equilibrium in the entry game, two sub-scenarios should be analyzed considering the Entrant's strategies, $a_{1}$ and $a_{0}$, against the Incumbent's any pooling strategy.

\section{Sub-scenario 2.1: Entrant chooses $a_{1}$ under $p>K_{E}-\theta_{E} / \theta^{E}-\theta_{E}$.}

There are two perfect Bayesian equilibrium outcomes. The first one is the uncommunicative, pooling equilibrium, in which all messages are uninformative and the Entrant chooses $a_{1}$ in both types. In the other equilibrium, the Incumbent reveals its type, and the Entrant takes the appropriate action, $a_{1}$ or $a_{0}$. In this separating equilibrium, all messages are informative such that neologisms $n\left(\mathrm{FLI}_{1}\right)$ and $\mathrm{n}\left(\mathrm{FLI}_{2}\right)$ are self-signaling. As noted in Farrell $(1985,1993)$, “...the preexisting common language should be analyzed assuming that there are meaningful neologisms". In the entry game, for every message that the Incumbent might want to announce, there are meaningful neologisms available, $\mathrm{n}\left(\mathrm{FLI}_{1,2}\right)$, whose literal meaning is that Incumbent's types lie in $\mathrm{FLI}_{1,2}$.

Apart from the meaning of the messages, Farrell $(1985,1993)$ discusses credibility issue noting that "...Nothing requires players to take a neologism's literal meaning seriously, but it is focal and so a player might be wise to do so, if he believes that the other players is doing so". In the entry game, the Entrant believes what the Incumbent wanted the Entrant to believe 
since the player's interests sufficiently coincide if and only if $\Theta^{\mathrm{M}} \geq \Theta^{\prime}$. In the entry game, Incumbent wishes to have the Entrant to believe that Incumbent's types lie in the neologisms. The suggestions of Farrell (1993) can be adapted to the entry game: The Incumbent would like the Entrant to believe its message if and only if it is true. Therefore, if the messages are selfsignaling, then the neologisms, $\mathrm{n}\left(\mathrm{FLI}_{1}\right)$ and $\mathrm{n}\left(\mathrm{FLI}_{2}\right)$, are credible and the Entrant should believe them.

To determine the neologism-proof equilibrium, the payoffs of two perfect Bayesian Nash equilibria (uncommunicative and informative) should be considered.

\begin{tabular}{ccc} 
Entrant's Action & Payoff to $t_{H}$ & Payoff to $t_{L}$ \\
\hline$a_{1}\left(t_{H}\right)$ & $\theta^{\prime}$ & - \\
$a_{0}\left(t_{L}\right)$ & - & $\theta_{M}$ \\
$a_{1}(T)$ & $\theta^{\prime}$ & $\theta_{I}$
\end{tabular}

The Entrant has two different actions: $a_{1}\left(t_{H}\right)$ and $a_{0}\left(t_{L}\right)$ are the best actions when the Entrant is sufficiently confident that Incumbent is of $t_{H}$ and $t_{L}$, respectively. If the all the messages are uninformative, then $a_{1}(T)$ is the best action under the $p>$ $\mathrm{K}_{\mathrm{E}}-\Theta_{\mathrm{E}} / \Theta^{\mathrm{E}}-\Theta_{\mathrm{E}}$. In uncommunicative equilibrium, Entrant maintains the prior beliefs. In this equilibrium, as noted in Farrell (1993), the posterior beliefs of the receiver never place enough weight on either type to justify choosing the actions.

In sub-scenario 2.1, the uncommunicative equilibrium is not neologism-proof, since both players are better off in $t_{L}$ in the informative neologism proof equilibrium $\left(0>\theta_{E}-K_{E}\right.$ and $\left.\theta_{M}>\theta_{1}\right)$. A neologism is only defined relative to a given equilibrium. Farrell (1993) notes that "...the very existence of a credible self-signaling neologism makes an equilibrium not neologismproof". In the entry game, the self-signaling neologisms available in the equilibrium are credible and the Incumbent has an incentive to employ them. Hence, the putative equilibrium is not self-enforcing. In the entry game, the informative neologismproof equilibrium rules out the implausible uncommunicative equilibrium.

Alignment of the players' preferences equips the FLI a coordinative function, enriching the language and providing credibility. In this scope, the Incumbent is able to influence the Entrant's choice of action by disclosing FLI and the Entrant is able to guess the Incumbent' type via FLI to choose its optimal action.

Sub-scenario 2.2: Entrant chooses $a_{0}$ under $p<K_{E}-\theta_{E} / \Theta^{E}-\theta_{E}$.

Here again, there are two perfect Bayesian equilibrium outcomes: uncommunicative, pooling equilibrium in which the Entrant maintains the prior beliefs and informative, separating equilibrium in which the Incumbent reveals his type. Again, in the informative equilibrium, the messages are self-signaling; the neologisms, $n\left(F L I_{1}\right)$ and $n\left(F_{2} I_{2}\right)$, are credible and the Entrant believes them. To determine the neologism-proof equilibrium, the payoffs of two perfect Bayesian Nash equilibria are listed as follows:

\begin{tabular}{ccc} 
Entrant's Action & Payoff to $t_{H}$ & Payoff to $t_{L}$ \\
\hline$a_{1}\left(t_{H}\right)$ & $\Theta^{\prime}$ & - \\
$a_{0}\left(t_{L}\right)$ & - & $\Theta_{M}$ \\
$a_{0}(T)$ & $\Theta^{M}$ & $\theta_{M}$
\end{tabular}

In the entry game, separating equilibrium exists if and only if $\Theta^{\mathrm{M}} \geq \Theta^{\prime}$. In the sub-scenario 2.2 , separating equilibrium fails to be neologism-proof, since the minimum possible value of $\Theta^{M}$ is equal to the maximum value of $\Theta^{\prime}$ under the condition of $\Theta^{M}$ $\geq \Theta^{\prime}$. In other words, Entrant's action $a_{0}$ in $t_{H}$ always ensures a gain for the Incumbent at least the maximum value of $\Theta^{\prime}$. By adopting the pooling strategy, the Incumbent ensures that the Entrant always chooses a. Thus, as noted in Farrell (1993), neologism-proof equilibrium need not to be more informative. The Incumbent prefers the Entrant not to be confident about its types and not be able to make any inferences.

\section{CONCLUSION}

Forward-looking information (FLI) is regarded as cheap-talk since the disclosure of subjective and non-accounting parts of such information have non-binding, non-verifiable and costless character. This paper investigates how and to what extent, the informational signaling mechanism of cheap-talk in the form of FLI can affect the payoffs in an entry game. The paper determines the equilibrium results. The analysis of pooling equilibrium gives evidence that the payoff level has clearly an encouraging effect, while the entry cost has a discouraging effect on the choose of entry. The choose of "enter" or "not enter" inherently emerges as a result of various combinations of the opposite effects along with the predictions about future, expressed in posterior beliefs. 
Even if the Entrant believes that unfavorable future conditions will most probably exist, the Entrant prefers to choose entry when the entry cost is sufficiently low. Contrarily, even if the Entrant believes that the favorable future conditions will likely exist, the Entrant would restrain to enter when the entry cost is relatively high. Sufficiently low amounts of entry cost overcome the Entrant's pessimism about future, while its relatively high amounts overshadow the Entrant's optimism.

The paper also analyzes the Entrant's payoff under optimistic or pessimistic predictions about future. If the Entrant's payoff sufficiently increases, the Entrant becomes more biased to choose entry as part of the optimal strategy even for high amounts of entry cost and/or despite pessimistic predictions regarding the future conditions. Contrarily, if the payoff relatively decreases, the choose of entry becomes not preferable even for low amounts of entry cost and/or despite optimistic predictions, and hence, the Entrant's tendency to stay out of the market also increases. On one hand, given the pessimistic predictions, the payoff should be at a level to cover the entry cost; while on the other hand, given the entry cost, the payoff should be at a level to overcome the pessimistic predictions to encourage the market entry.

Thus, analyzing the interactive relations among the entry cost, payoff levels and the predictions about the future market conditions in an entry game setting, this paper enhances the understanding the competition dynamics in duopoly and oligopoly markets. In fact, none of these variables alone determine the firms' strategies in a competitive market. Rather, the combinatory effects of these variables have varied implications on the strategic decisions and hence, the competitive dynamics in the market. In the market especially characterized by duopoly or oligopoly competition, the paper indicates that entry cost, payoff levels and the market predictions have to be analyzed in an integrated manner in order to make strategic analysis about the competitive conditions.

This paper also analyzes the meaning and credibility of FLI as the building blocks of neologism-proofness criteria. Payoff structure of the entry game partly fulfills the necessary conditions of Crawford and Sobel (1982) for FLI to be informative. In this scope, the first condition is not satisfied since the Incumbent types have the same preferences over the actions. However, the second and third conditions are satisfied: The Entrant prefers the different actions depending on the Incumbent's type, and the Entrant's preferences over actions are not completely opposed to Incumbent's. As the common characteristic of cheap-talk games, pooling equilibrium exists in the entry game, but not the separating equilibrium. However, this paper indicates in an alternative scenario that informative separating equilibrium exists when the players' preferences are sufficiently aligned by satisfying all necessary conditions of Crawford and Sobel (1982) in the entry-game.

Neologism-proofness criteria is also applied to refine equilibria under two scenarios. In the first scenario in which only the pooling equilibrium exists, this uncommunicative perfect Bayesian equilibrium is neologism-proof. In the second scenario involving both the pooling and separating equilibria, the equilibrium which satisfies the neologism-proofness criteria, depends on the Entrant's strategy. The potential Entrant will be able to choose either "enter" or "not-enter" if its posterior beliefs never place enough weight on either type to justify choosing the actions in equilibrium.

Under entry strategy, the paper indicates that the informative equilibrium is neologism-proof, which breaks the implausible uncommunicative equilibrium. The alignment of the players' preferences adds a meaning to communication and the meaningful communication has a coordinative role that makes the uncommunicative equilibrium implausible in the entry game. Under the entry strategy, the Incumbent should disclose its private information. The self-signaling neologisms available in the equilibrium are credible and thus, the Incumbent has an incentive for truthful announcement and the Entrant has a reason to believe in. Contrarily, under non-entry strategy, separating equilibrium fails to be neologism-proof. The Incumbent prefers the Entrant not be able to make any inferences about its types. Under non-entry strategy, the incumbent should not reveal its private information. In conclusion, the entry game involves a strategic communication between an Incumbent and a potential Entrant. In this communication, both pooling and separating equilibria satisfy neologism-proofness criteria depending on the alternative scenarios in the entry game.

\section{REFERENCES}

AICPA (1994) Improving business reporting - a customer focus: meeting the information needs of investors and creditors, Comprehensive Report of the Special Committee on Financial Reporting (The Jenkins Report). American Institute of Certified Public Accountants. Retrieved from https://egrove.olemiss.edu/aicpa_comm/102/

Baginski, S.P. Hassell J.M. \& Kimbrough, M.D. (2004). Why do Managers explain their earnings forecasts? Journal of Accounting Research. 42: 1-29. Doi: 10.1111/j.1475-679X.2004. 00127.x

Baginski, S., Demers, E. Wang C. \& Yu J. (2016). Contemporaneous verification of language: evidence from management earnings forecasts. Review of Accounting Studies. 21(1): 165-197. DOi: 10.1007/s11142-015-9347-6

Banks, J.S. \& Sobel, J. (1987). Equilibrium selection in signaling games. Econometrica 55: 647-661. DOi: 10.2307/1913604 
Beattie, V. McInnes, B. \& Fearnley, S. (2004). A methodology for analyzing and evaluating narratives in annual reports: a comprehensive descriptive profile and metrics for disclosure quality attributes. Accounting Forum. 28: 205-236. D0i: 10.1016/j.accfor.2004.07.001

Chen, Y. Kartik, N. \& Sobel, J. (2008). Selecting cheap-talk equilibria. Econometrica. 76: 117-136. D0i: 10.1111/j.0012-9682.2008. 00819.x

Cho, I.K. \& Kreps, D. (1987). Signaling games and stable equilibria. Quarterly Journal of Economics. 102: 179-221. DOi: 10.2307/1885060.

Clarkson, P. M., Kao, J.L. \& Richardson, G.D. (1999). Evidence that management discussion and analysis (MD\&A) is a part of a firm's overall disclosure package. Contemporary Accounting Research. 16: 111-134. DOi: 10.1111/j.1911-3846.1999.tb00576.x

Clatworthy, M.A. \& Jones, M. J. (2006). Differential patterns of textual characteristics and company performance in the chairman's statement. Accounting, Auditing \& Accountability Journal. 19: 493-511. DOi: 10.1108/09513570610679100.

Crawford W.P. \& Sobel, J. (1982). Strategic information transmission. Econometrica. 50: 1431-1451.

Crawford, V. (1998). A survey of experiments on communication via cheap-talk. Journal of Economic theory. 78: 286-298. Doi: 10.1006/jeth.1997.2359

de Groot Ruiz, A. Offerman, T. \& Onderstal, S. (2015). Equilibrium selection in experimental cheap-talk games. Games and Economic Behavior. 14-25. DOi: 10.1016/j.geb.2015.03.011

D'Augusta, C. \& DeAngelis, M. D. (2020). Does accounting conservatism discipline qualitative disclosure? evidence from tone management in the MD\&A (March 10, 2020). Contemporary Accounting Research, Forthcoming, SSRN: https://ssrn.com/abstract=3555122

Darrough, M. N. (1993). Disclosure policy and competition: cournot vs bertrand. Accounting Review. 68: 534-561. DOI: 10.2307/248200

Darrough, M.N. \& Stoughton, N.M. (1990). Financial disclosure policy in an entry game. Journal of Accounting and Economics. $12: 219-243$. Doi: 10.1016/0165-4101(90)90048-9.

Farrell, J. (1985). Credible neologisms in games of communication. Working Paper No. 386, MIT

Farrell, J. (1987). Cheap-talk, coordination, and entry. Rand Journal of Economics. 18: 34-39.

Farrell, J. (1993). Meaning and credibility in cheap-talk game. Games and Economic Behavior. 5: 514-531.

Farrell, J. \& Gibbons, R. (1989). Cheap-talk can matter in bargaining. Journal of Economic Theory. 48: 221-237. Doi: 10.1016/00220531(89)90125-7

Feltham G.A. \& Xie J.Z. (1992). Voluntary Financial disclosure in an entry game with continua of types. Contemporary Accounting Research. 9: 46-80. DOi: 10.1111/j.1911-3846.1992.tb00869.x

Frankel, R. McNichols, M. \& Wilson, P. (1995). Discretionary disclosure and external financing. The Accounting Review. 70: 135-150. DOi: $10.2307 / 248392$

Fudenberg, D. \& Tirole J. (1991). Perfect bayesian equilibrium and sequential equilibrium. Journal of Economic Theory. 53: 236-260. DOi: 10.1016/0022-0531(91)90155-W.

Gibbons, R. (1992). Game theory for applied economists. Princeton University Press.

Gigler, F. (1994) Self-enforcing voluntary disclosures. Journal of Accounting Research. 32: 224-240. DOi: 10.2307/2491283

Harsanyi, J.C. (1967). Games with incomplete information played by "bayesian" players, part I: the basic model. Management Science. 14: 159-182. Doi: $10.1287 /$ mnsc.14.3.159

Harsanyi, J.C. (1968). Games with Incomplete information played by "bayesian" players, part II: bayesian equilibrium points. Management Science. 14: 320-334. DOi: 10.1287/mnsc.14.5.320

Kent, P. \& Ung, K. (2003). Voluntary disclosure of forward-looking earnings information in Australia. Australian Journal of Management. 28: 273-285. DOi: 10.1177/03189620302800303.

Kim, J.W. \& Shi, Y. (2011). Voluntary disclosure and the cost of equity capital: evidence from management earnings forecasts. Journal of Accounting and Public Policy. 30: 348-366. DOi: 10.1145/3226116.3226140.

Lev, B. \& Penman, S.H. (1990). Voluntary forecast disclosure, nondisclosure, and stock prices. Journal of Accounting Research. $28: 49-75$. DOI: $10.2307 / 2491217$.

Li, Y. Li, C. \& Gao, Y. (2020). Voluntary disclosures and peer-to-peer lending decisions: Evidence from the repeated game. Frontiers of Business Research in China. 14(7). Retrieved from https://link.springer.com/article/10.1186\%2Fs11782-020-00075-5

Matthews, S. Okuno-Fuji M. \& Postlewaite, A. (1991). Refining cheap-talk equilibria. Journal of Economic Theory. 55: $247-73$. 
Newman, P. \& Sansing, R. (1993). Disclosure policies with multiple users. Journal of Accounting Research. 31: 92-112. DOi: 10.2307/2491043 O'Sullivan M. Percy, M. \& Stewart, J. (2008). Australian evidence on corporate governance attributes and their association with forwardlooking information in the annual report. Journal of Management \& Governance. 12: 5-35. DOi: 10.1007/s10997-007-9039-0

Park, I.U. (2002). Cheap-talk coordination of entry by privately informed firms. Rand Journal of Economics. 33: 377-393. Doi: $10.2307 / 3087463$

Rabin, M. (1990). Communication between rational agents. Journal of Economic Theory. 51: 144-170. D0i: 10.1016/0022-0531(90)90055-O.

Rabin, M. \& Sobel, J. (1996). Deviations, dynamics, and equilibrium refinements. Journal of Economic Theory. 68: 1-25. Doi: 10.1006/jeth.1996.0001

Stocken, P.C. (2000). Credibility of Voluntary Disclosure, RAND Journal of Economics, 31(2): 359-374

Verrecchia, R.E. (1983). Discretionary disclosure. Journal of Accounting and Economics. 5: 179-194. D0i: 10.1016/0165-4101(83)90011-3.

Wagenhofer, A. (1990). Voluntary disclosure with a strategic opponent. Journal of Accounting and Economics 12: 341-363. DOi: $10.1016 / 0165-4101(90) 90020-5$ 